\section{Carbon dioxide sampling error due to leaking $O$-ring?}

To the Editor:

We wish to report an equipment problem that led to misinterpretation of $\mathrm{ETCO}_{2}$ measurements.

During uneventful low-flow anaesthesia, the Ohmeda 5200 carbon dioxide monitor alarmed, reporting a blocked sampling line. Investigation traced the blockage to the water filter, and this was replaced. Shortly after this replacement, it was noted that the monitor reported both an $\mathrm{ETCO}_{2}$ concentration of 22 $\mathrm{mmHg}$ (instead of the previous $35 \mathrm{mmHg}$ ), and a nitrous oxide concentration varying between $29 \%$ and $35 \%$ (instead of $65 \%$ ). Gently lifting or twisting the water filter brought the reported nitrous oxide concentration up to $65 \%$ and the $\mathrm{ETCO}_{2}$ up to $40 \mathrm{mmHg}$ (the minute volume had been reduced unnecessarily). This manoeuvre suggested that the $\mathrm{O}$-rings sealing the water filter to the machine sampling pipes were at fault, allowing entrainment of air to dilute the sampled gas. Visual inspection of the joint did not reveal any obvious abnormality. As replacement parts were not available, the presence of expired $\mathrm{CO}_{2}$ was monitored qualitativcly, with intermittent quantitative measurements made by adjusting the water filter until the nitrous oxide read $65 \%$. After an hour the gas dilution spontaneously ccased. Whether this was because the rubber O-rings had expanded sufficiently to seal the leak, or because moisture had collected in the gap is not clear.

The air entrainment led to a measurement of $\mathrm{ETCO}_{2}$ concentration which under more exacting clinical circumstances, such as during neurosurgery, could lead to patient harm. Our observation has been reported to Ohmeda.

J.E. Fletcher MB MRCP FRCA

J.M.T. Foster MB FRCPC

C.M.B. Heard MB FRCA

The Children's Hospital of Buffalo

New York 14222-2099

\section{Erratum}

Lerman J. Study design in clinical research: sample size estimation and power analysis. Can J Anaesth 1996; 43: 184-91.

The calculation of $\phi$ for each proportion in equation 2 is based on the expression: $\phi=2 \times \arcsin \sqrt{P}$. The factor, 2 , was inadvertently omitted from the description of $\phi$ on page 186. 